Review Article

\title{
SURFACTANT MATERIAL PROPERTIES AND CORONAVIRUS SURFACE: A SURFACE INTERACTION FOR COVID-19 TREATMENT AND VACCINATION
}

\author{
FIRDOOS AHMAD ITO0a, JAN MOHAMMAD MIR
}

aDepartment of Chemistry, Govt. Degree College, Udhampur, J and K, India, bCoordination, Metallopharmaceutical and Computational Chemistry Laboratory, Department of PG Studies and Research in Chemistry and Pharmacy, R. D. University, Jabalpur, MP, India Email: mirjanmohammad@gmail.com

Received: 16 Jun 2021 Revised and Accepted: 31 Aug 2021

\section{ABSTRACT}

Generally, the structural components of infectious diseases causing viruses like coronavirus, Ebola virus, etc., are mainly focused on developing effective treatment and vaccines. Meanwhile, the spike proteins play a major role in knowing the profound way out to curtail the respective infectivity. S1 and S2 act as the two main subunits to render prime significance to reveal the interaction of surface-active agents in this context. Keeping in view the importance of surfactants in developing effective treatment and vaccine for the coronavirus infectious disease-2019 (COVID19), this article describes the surface chemistry of this quest. The surface action being the main mode of infectivity can thus be halted by using surface-active compounds (surfactants). Therefore, this review emphasizes the sound role of surface action linked with COVID-19 treatment and vaccination.

Keywords: Surfactants, COVID-19, Coronavirus, Surface action, Sanitizer, Vaccines, Treatment

(C) 2021 The Authors. Published by Innovare Academic Sciences Pvt Ltd. This is an open access article under the CC BY license (http://creativecommons.org/licenses/by/4.0/] DOI: http://dx.doi.org/10.22159/ijcr.2021v5i4.181. Journal homepage: https://ijcr.info/index.php/journal

\section{INTRODUCTION}

The emergency treatment of the coronavirus infectious disease-2019 (COVID-19) pandemic affected people was mainly led by focusing on the repurposing of older drugs having distinguished marketing authorization (MA) to act as therapeutic options for other indications. This repositioning of drugs made follow-up for fast-track clinical trials. The redundant hurried, and biased methodologies in the context of such investigations brought up premature publications. Due to limited sample size and other factors, including questionable conclusions with less efficacy, several reports have developed uncertainty [1]. Every field of science tries to find the applicability in halting this dreadful infection. Similarly, surface chemistry plays the main pivotal role in developing effective medication for this pandemic. Hence to end these apocalyptic times, the entire scientific community must unite. The unique composition of surfactants is integrally related to their surface-active property, which plays a critical role in host defense. Hence, such functionalities provide lung stability and protection from a barrage of potentially virulent infectious pathogens. Naturally-occurring surfaceactive molecules such as proteins that behave as surfactants [2] and saponins [3] have shown significant bactericidal and antiviral behavior. Surfactant's structural behavior motivates to study of the interactions between virus particles and various classes of surfactants. The possible mechanisms may provide a way forward to Viruses deactivation or stabilization. Surfactants micellar aggregation in aqueous solution depending on the molecular and electrolytic solvent environment may offer the opportunity to control the menace of the virus. Surfactant binding to folded or unfolded proteins can influence micelle formation by the development of surfactant-protein structures in addition to free micelles [4,5]. Some micelles can entrap and solubilize other molecules or particles [6]. Bound surfactants can modify the apparent surface charge of nanoparticles [7] and therefore influence the interactions and aggregation of these particles in solution. Because proteins (through electrostatic interaction) possess hydrophobic, hydrophilic, anionic, and cationic regions, they can hence act as strongly bind both anionic and cationic surfactants.

Surfactants with charged head groups can alter the effective surface charge of surfaces or particles by shielding opposite directions or adding charge to a hydrophobic site [8]. The high surface activity of surfactants allows them to dictate the chemical stability of applied interest [9, 10]. Due to the growing motivation towards contemporary COVID-19 related scientific temper [11-14], this article has been dedicated to finding the applicability of surface chemistry to aid in designing and developing anticovid drugs and efficacious vaccines for all-time defensive against this dreadful pandemic.

Literature coverage (1986 to 2021); Source: World famous journals published, Internet, COVID-helpline HTML and NEW-YORK Times News Paper

\section{The general outlook of virus}

A virus is a submicroscopic infectious agent that replicates only inside the living cells of an organism [15]. Viruses infect all life forms, from animals and plants to microorganisms, including bacteria and archaea [16]. Overall, the characterization of the colloidal interactions, dispersion state, and integrity of the virus particles may provide valuable data in understanding pathogenicity trends and aiding in developing strategies to prevent virus spread. Characterizing Norovirus behavior is especially important due to its unique resiliency in many different chemical environments. It appears that simple adjustments in the $\mathrm{pH}$, salt conditions, and addition of common surfactants to cleaning and antiviral products can assist in preventing outbreaks and treating coronavirus as an infectious agent. Influenza viruses are important causes of seasonally occurring epidemics of febrile respiratory disease. Both cellular and humoral immunity are evoked after infection [17]. Cellular immunity seems to be involved mainly in the eradication of the virus in established infection. In contrast, protective immunity is mediated by antibodies that are directed against hemagglutinin (HA), the major viral surface glycoprotein. However, mutations in the HA genome may cause antigenic changes of the viral HA, resulting in the appearance of new variants of the virus [18]. Hence, previously protected persons become susceptible to new influenza virus infections.

Covid-19 pandemic outbreak and sars-cov-2 virulence

In December 2019, the novel coronavirus infection was first detected in Wuhan, Hubei Province, China. This infectious disease is widely known as COVID-19 or nCOVID and has widely spread in the whole world. On 31st December 2019, high authorities of China alerted WHO with an alarming signal conveying the outbreak of a new strain of coronavirus, responsible for severe illness similar to SARS-CoV-1, and was hence named as SARS- 
CoV-2. COVID-19 is currently accepted as a high transmitting infectious disease. Though the actual source of this infection is unknown yet, the high communicability and millions of deaths by this disease defeated the whole world. The dynamics are not clear yet, but several assumptions have been made showing the virus to have an animal origin. The coronavirus has been found to have an elliptic or round shape. It is mostly referred to as pleomorphic (in microbiology, the pleomorphic microorganism can change morphology, functional status, or modes of reproduction with respect to environmental conditions). The virus has a diameter of 60-140 nm approximately. Generally, coronaviruses are UV and heat-sensitive. The genetic analysis has shown a resemblance of $86 \%$ of the whole genome of SARS-CoV-2 with SARS-CoV-1. Studies conducted on seeking the mechanistic details of SARS-CoV-2 virulence have confirmed the respective affinity towards the structural and nonstructural proteins (SP and Nsps). For example, the underlined research indicated that (Nsps) possess the ability to impair and affect the host's innate immune response [12-14].

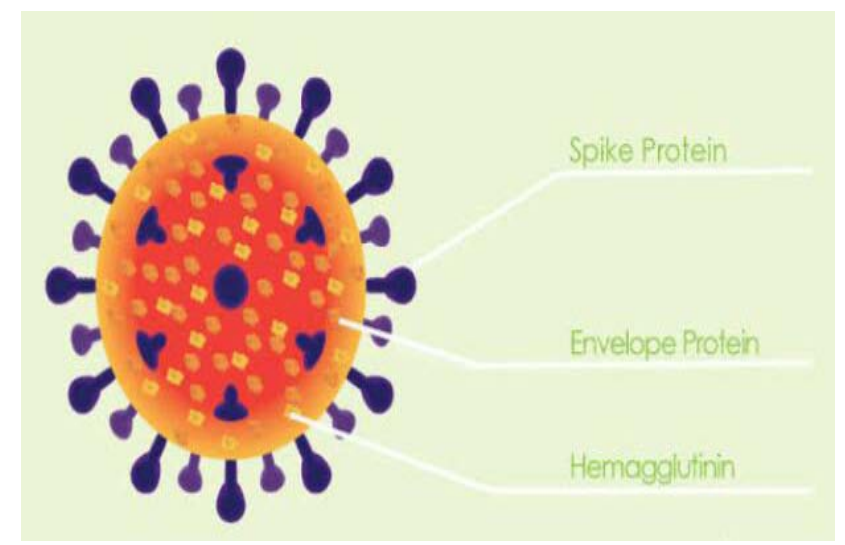

Fig. 1: Viral structure of COVID-19 causing virus (Adapted from reference 14)

Fig. 1 displays the structural diagram of the virus along with the structural and nonstructural protein parts. The main part of the virus involved in pathogenicity is its envelope because it is the key supporting assembly for viral release. Secondly, the biological interaction through specific enzyme intervention viz the angiotensin-converting enzyme-2 (ACE2) located on humans' lower respiratory tract cells has a direct link for receptors to conduct endocytosis for SARS-CoV-2 in COVID-19. Among the different structural components of the virus, the constituent spike glycoprotein (S) mainly consists of S1 and S2 subunits. The S-protein homotrimers are arranged on the virus's surface, wholly termed envelopes representing the leading ink used for host receptor susceptibility. The S2 subunit is highly conserving for being a site of fusion peptide along with the transmembrane domain and the cytoplasmic region. Therefore for design anticoronavirus agents, S2 is the main target to deactivate. Other structural proteins are found only in COVID-19, causing viruses to include ORF3b, and ORF8 encoded proteins. The latest research on receptorbinding domain (RBD) part of the virus S-proteins reveals efficiently targeting feature at the molecular level feature on ACE2 receptors. These receptors have a key role in blood pressure maintenance. The SARS-CoV-2 S-protein has got such an effective binding potential with the human cells. The entire world community of scientists remarked this due to natural selection with no implications of a genetically engineered product.

\section{Viral invasion and immune response}

To understand how vaccines work, we should first look at how the body fights illness. When germs, such as bacteria or viruses invade the body, they attack and multiply. This invasion is called an infection, and that is what causes illness. Our immune system uses several tools to fight infection. As our blood contains red blood cells for carrying oxygen to tissues and organs and white or immune cells for fighting infection, these white cells consist primarily of macrophages, B-lymphocytes, and T-lymphocytes. The Macrophages are white blood cells that swallow up and digest germs, plus dead or dying cells. These macrophages leave behind parts of the invading germs called antigens. The body identifies antigens as dangerous and stimulates antibodies to attack them. The B-lymphocytes of white blood cells is defensive as they produce antibodies that attack those antigens left behind by the macrophages. Similarly, T-lymphocytes are another type of defensive white blood cell. They also attack those cells in the body which have already been infected. The first time the body encounters a germ takes several days to make and use all the germ-fighting tools needed to get over the infection. After the illness, the immune system remembers what it learned about protecting the body against that disease. The body keeps a few T-lymphocytes, called memory cells, that go into action quickly if the body encounters the same germ again. When the familiar antigens are detected, B-lymphocytes produce antibodies to attack them (fig. 2).

A virus is a small parasite that cannot reproduce by itself. Once it infects a susceptible cell, a virus can direct the cell machinery to produce more viruses. Most viruses have either RNA or DNA as their genetic material. The nucleic acid may be single-or double-stranded. The entire infectious virus particle, called a virion, consists of nucleic acid and an outer shell of protein. The simplest viruses contain only enough RNA or DNA to encode four proteins. The most complex can encode 100-200 proteins. 

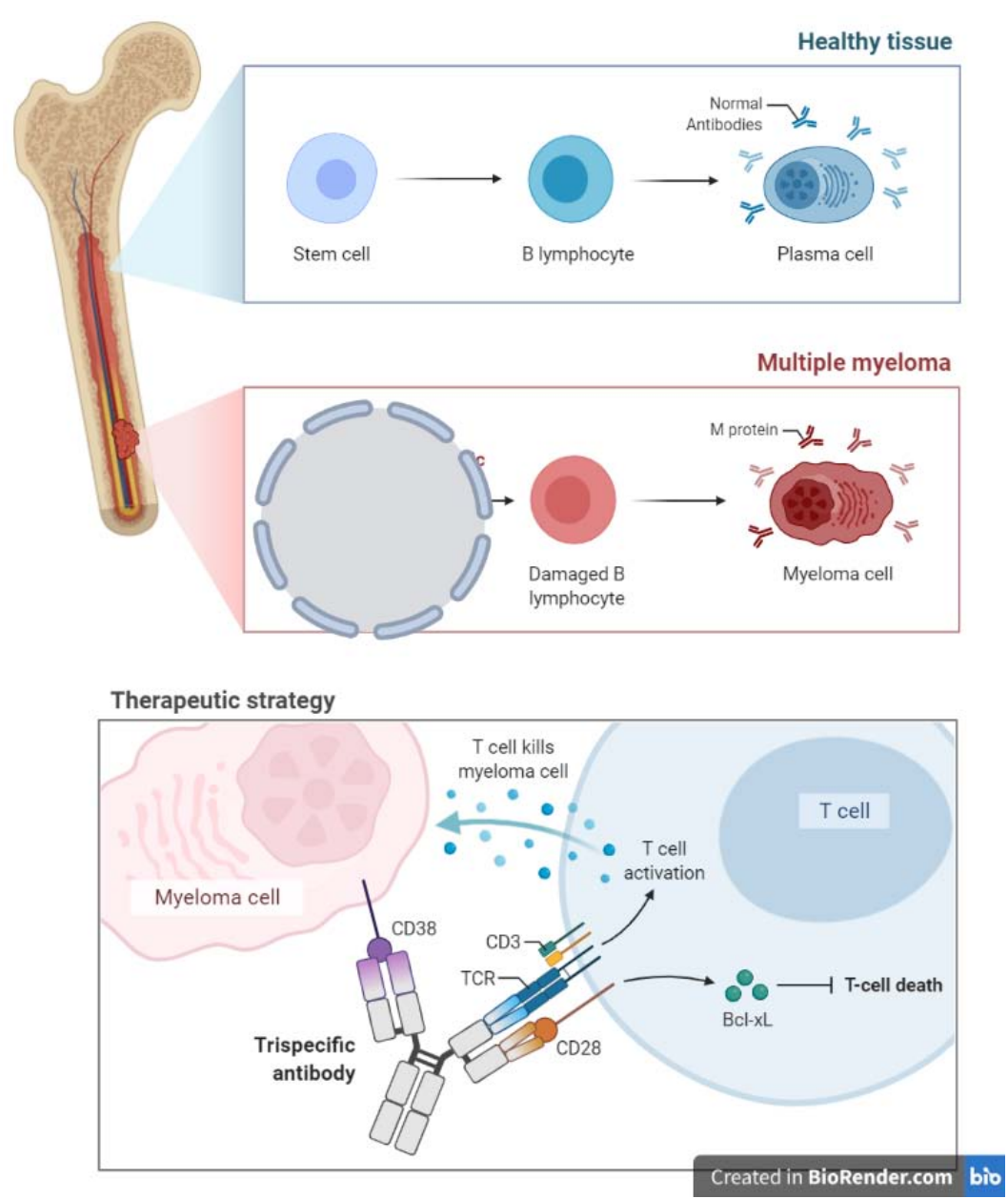

Fig. 2: Immune responsiveness (Constructed in Biorender. com)

\section{Surfactants' role in controlling the coronavirus disease}

Scientific world has left no stone unturned to find the perfect treatment and efficacious vaccine for the prevailing COVID-19 pandemic. The infectivity of this disease has encompassed the globe as a whole, indicating the very high rapid communicability of the causative virus (Coronavirus). Several instructions are imperative to restrict this infectious disease, including the frequent washing using soap/detergent for maintaining hygiene to prevent COVID-19 spread. Since the surface interaction plays the main role and damaging spike protein of coronaviruses is the main key to inactivate the virus [19]. The surface-active agents, including soaps/detergents, are hence important under such criteria. Meanwhile, experimental data collected for Ebola virus inactivation (spike-protein mediated) stems from this assumption as an ideal hypothesis for the novel Coronavirus [20]. Surfactants are widely known to have a main role in the pharmaceutical industry. In this context, several bio-surfactants possess fascinating antiviral properties. In special attention to COVID-19 causing virus, this potentiality is still unexplored. Hence, the above said hypothesis could establish possible use of such scaffolds against SARS-CoV-2 surface proteins to seek the efficacious treatment for this disease (fig. $3)$.

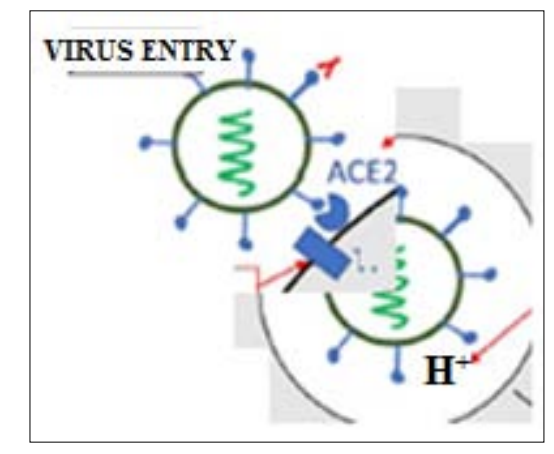

Fig. 3: Corona surface action (self-created) 
Hand hygiene by washing with soap and water is recommended for the prevention of COVID-19 spread. Soaps and detergents are explained as damaging viral spike glycoproteins (peplomers) or by washing out the virus through entrapment in the micelles. Technically, soaps come under a functional category of molecules known as surfactants. Surfactants are widely used in pharmaceutical formulations as excipients. Do we wonder why surfactants are still not tried for prevention or therapy against COVID-19? That too when many of them have proven antiviral properties. Moreover, lung surfactants have already shown benefits in respiratory viral infections. Therefore, we postulate that surfactant-based prophylaxis and therapy would be promising. We believe that our hypothesis would stimulate debate or new research exploring the possibility of surfactantbased prevention and treatment against COVID-19. The success of a surfactant-based technique would save the world from any such pandemic in the future too.

Besides its role in maintaining the conduit for air to and from the alveoli, the airway epithelium is central to the defense of the lung against pathogens through the combined function of ciliated epithelial and secretory cells maintaining efficient mucociliary clearance and through a variety of other host defense mechanisms. As the first line of defense, the airway epithelium can be considered a soldier is fighting against airborne pathogens. Airway epithelial cells regulate both innate and adaptive immunity by producing functional molecules and physical interactions with cells of the immune system. Activation of epithelial cells results in immediate host defense responses that include the production of antiviral substances and pro-inflammatory cytokines, which recruit and activate other mucosal innate immune cells and initiate mechanisms of adaptive immunity [21].

In many cases, infection will induce flu-like symptoms in the host who will additionally become highly contagious, having an averaged R0 of roughly 3.28 , even throughout the initial incubation period, which has been suggested to last up to 3-14 $\mathrm{d}[22,23]$. The major route of entry of SARS-CoV-2 is through the nose and mouth, and to some extent, through the eyes. The throat (pharynx) is a common point of access to the lungs from both mouth and nose. In the case of eyes, too, it is described that the virus travels through the lacrimal and nasolacrimal ducts (the tear ducts) and then into the nose, throat, trachea, and finally lung [24]. Thus, any virus accidentally entered through the mouth, nose, and/or eyes could be stopped/inactivated at the pharynx or nasopharynx using a surfactant-based gargle cleansing action of surfactants via surfactants-Virus interactions. All ages are susceptible. Infection is transmitted through large droplets generated during coughing and sneezing by symptomatic patients but can also occur from asymptomatic people and before the onset of symptoms [25]. Studies have shown higher viral loads in the nasal cavity than the throat, with no difference in viral burden between symptomatic and asymptomatic people [26].

\section{Surfactant therapy for respiratory illness}

Among several treatments, this therapy is already in use for respiratory problems. It is reported that inhalation of lung surfactants improves respiratory diseases. The tremendous benefit of an artificial surfactant against the HINI virus has been proved in mice [27]. Also, surfactants have some role in innate host defense during infections [28]. It could be reasonably hypothesized that surfactant therapy would be promising in COVID19 cases. A list of approved lung surfactants Colfosceril palpitate, breakfast, lucinactant, and recombinant human surfactants protein C. polysorbate, poloxamer, sodium lauryl sulfate, Certificate, Bile Salt Surfactants, Phospholipids, Vitamin E TPGS, Polyoxyl 35 castor oil [29-36].

\section{Surface chemistry and working of vaccines}

Vaccines prevent diseases that can be dangerous or even deadly. They greatly reduce the risk of infection as they are working with the body's natural defense system to develop immunity to disease safely. Vaccines help develop immunity by imitating an infection. Once the imitation infection goes away, the body is left with a supply of "memory" T-lymphocytes, as well as B-lymphocytes that will remember how to fight that disease in the future. However, the current scenario shows that many people who got vaccinated still got infected by the coronavirus; in such case, it is possible that a person infected with a disease just before or just after vaccination developed symptoms and got infected again probably the vaccine has not had enough time to provide protection. Below is the study copied from New York Times on April 20,2021, wrote under the heading "Coronavirus Vaccine Tracker" by Carl Zimmer, Jonathan Corum, and Sui-Lee Wee (table 1).

Table 1: Vaccination clinical phases and administration statuses

\begin{tabular}{|c|c|c|c|}
\hline Vaccine & Working part & Clinical phase & Administration status \\
\hline Pfizer-BioNTech & mRNA & 23 & Approved in several countries. Emergency use in U. S., E. U., other countries. \\
\hline Moderna & mRNA & 3 & Approved in Switzerland. Emergency use in U. S., E. U., other countries. \\
\hline Gamaleya & Ad26, Ad5 & 3 & Early use in Russia. Emergency use in other countries. \\
\hline Oxford-Astra Zeneca & ChAdOx1 & 23 & $\begin{array}{l}\text { Approved in Brazil. Stopped use in Denmark. Emergency use in U. K., E. U., other } \\
\text { countries. }\end{array}$ \\
\hline CanSino & Ad5 & 3 & Approved in China. Emergency use in other countries. \\
\hline Johnson and Johnson & $\operatorname{Ad} 26$ & 3 & Emergency use in U. S., E. U., other countries. Paused in some states and countries. \\
\hline Vector Institute & Protein & 3 & Early use in Russia. Approved in Turkmenistan. \\
\hline Novavax & Protein & 3 & \\
\hline Sinopharm & Inactivated & 3 & Approved in China, U. A. E., Bahrain. Emergency use in other countries. \\
\hline Sinovac & Inactivated & 3 & Approved in China. Emergency use in other countries. \\
\hline Sinopharm-Wuhan & Inactivated & 3 & Approved in China. Limited use in U. A. E. \\
\hline Bharat Biotech & Inactivated & 3 & Emergency use in India, other countries. \\
\hline
\end{tabular}

Vaccines typically require years of research and testing before reaching the clinic, but in 2020, scientists embarked on a race to produce safe and effective coronavirus vaccines in record time. Researchers are currently testing 89 vaccines in clinical trials on humans, and 23 have reached the final stages of testing. At least 77 preclinical vaccines are under active investigation in animals.

\section{Preclinical testing}

Scientists test a new vaccine on cells and then give it to animals such as mice or monkeys to see if it produces an immune response.

Phase 1 safety trials: Scientists give the vaccine to a small number of people to test safety and dosage and confirm that it stimulates the immune system.

Phase 2 expanded trials: Scientists give the vaccine to hundreds of people split into groups, such as children and the elderly, to see if the vaccine acts differently in them. These trials further test the vaccine's safety. 
Phase 3 efficacy trials: Scientists give the vaccine to thousands of people and wait to see how many become infected, compared with volunteers who received a placebo. These trials can determine if the vaccine protects against the Coronavirus, measuring what's known as the efficacy rate. Phase 3 trials are also large enough to reveal evidence of relatively rare side effects.

Early or limited approval: Many countries have procedures for providing emergency authorizations for vaccines based on preliminary evidence that they are safe and effective. In addition, some countries such as China and Russia began administering vaccines before detailed Phase 3 trial data was made public. Experts have warned of serious risks from jumping ahead of these results.

Approval: Regulators review the complete trial results and plans for a vaccine's manufacturing and decide whether to give it full consent.

Combined phases: One way to accelerate vaccine development is to combine phases. Some vaccines are now in Phase $1 / 2$ trials. For example, this tracker would count as both Phase 1 and Phase 2 .

Paused or abandoned: If investigators observe worrying symptoms in volunteers, they can stay the trial. After an investigation, the trial may resume or be abandoned.

Callous Behavior of Commoner towards Coronavirus and its effects India recorded nearly270,000 new Covid-19 infections and fifteen hundred deaths (April 19-2021), the highest single-day jump in infections in over a year. The country is currently the world's highest contributor to fresh Covid-19 cases, with numbers worsening every day. The reason behind this jump is the irresponsible attitude of both government and the people of the place who participated overwhelmingly in political rallies and religious festivals without following the recommended standard operations (SOPs).

Since, at this time, several vaccines are approved for the treatment of this infection, prevention is still considered more crucial. Several properties of this virus make prevention difficult, namely, non-specific features of the disease, the infectivity even before the onset of symptoms in the incubation period, transmission from asymptomatic people, long incubation period, tropism for mucosal surfaces such as the conjunctiva, prolonged duration of the illness and transmission even after clinical recovery. Still Isolation of a person who is either confirmed or suspected with mild illness at home is recommended. The ventilation at home, Patients should be asked to wear a simple surgical mask and practice cough hygiene. Caregivers should be invited to wear a surgical mask when in the same room as the patient and use hand hygiene every 15-20 min. The greatest risk in COVID-19 is transmission to healthcare workers. These front-line warriors are giving their best, but the callous and irresponsible behavior of the people across the globe is increasing the pressure load on these warriors.

\section{CONCLUSION}

The world has reached a point where inhabitants are bound to understand that for their good; they have to follow the SOPs that WHO recommended from day one. If human beings ignore the guard against the Coronavirus, then many waves of the pandemic will ruin our life. The Coronavirus is mutating continuously, and this behavior of Coronavirus is challenging our vaccination program. Therefore, it is better to get vaccinated and follow the SOPs in letter and spirit until herd immunity is developed. The year 2020 witnessed a challenging period for worldwide scientists to find a suitable treatment for deadly novel coronavirus infectious disease-2019 (nCOVID or COVID-19). The entire scientific community has been eager to develop effective vaccines and medicine against COVID-19. Despite the administration of vaccination in several countries across the globe, the drug repurposing of several antiviral compounds yielded satisfactory results in recovering the affected people. As it is known that vaccination alone is not the end of this pandemic, but the definitive treatment in terms of drugs/medicines specific to this disease is yet underway. It looks worthy of presenting a literature survey based on the collective information related to the surfactant candidates repurposed, the respective theoretical evaluation, and some of the effective therapies for treating COVID-19. This review also describes vaccination availed so far. A few commercially available vaccines have also been introduced. Based on the survey, it is clear that the entire world must remain alert for any future pandemic keeping in view the successful and unsuccessful efforts practiced in the COVID-19 pandemic. It looks good to mention here a quotation displayed on the WHO website (January 12, 2021) that reads, "With a fast-moving pandemic, no one is safe, unless everyone is safe." In the several approaches brought to light through this survey, it is to mention here that viral strains are never stagnant; they keep on changing their functionality with respect to the environment. Therefore, scientists should be ready to encounter any pandemic like COVID-19 in the future. Very recently, several types of coronavirus strains have regenerated the COVID-19 fear-like situation. Several countries restarted lockdown strategies and physical distancing to prevent the people from this second coronavirus strain from having $70 \%$ more communicability than the previous form. Therefore, having reached the vaccination stage and bringing COVID-19 to control doesn't mean that we are safe.

\section{FUNDING}

Nil

\section{AUTHORS CONTRIBUTIONS}

All the authors have contributed equally.

\section{CONFLICT OF INTERESTS}

Declared none

\section{REFERENCES}

1. Couvreur P, Louvard D. COVID-19 and drugs: pathophysiology and therapeutic approaches. C R Biol. 2021;344(1):27-42. doi: 10.5802/crbiol.38, PMID 34213847.

2. White M, Kingma P, Tecle T, Kacak N, Linders B, Heuser J, Crouch E, Hartshorn K. Multimerization of surfactant protein D, but not its collagen domain, is required for antiviral and opsonic activities related to influenza virus. J Immunol. 2008;181(11):7936-43. doi: 10.4049/jimmunol.181.11.7936, PMID 19017984.

3. Vanitha V, Vijayakumar S, Nilavukkarasi M, Punitha VN, Vidhya E, Praseetha PK. Heneicosane- A novel microbicidal bioactive alkane identified from Plumbago zeylanica L. Ind Crops Prod. 2020;154. doi: 10.1016/j.indcrop.2020.112748, PMID 112748.

4. Turro NJ, Lei XG, Ananthapadmanabhan KP, Aronson M. Spectroscopic probe analysis of protein-surfactant interactions: the BSA/SDS system. Langmuir. 1995;11(7):2525-33. doi: 10.1021/la00007a035.

5. Otzen DE. Protein unfolding in detergents: effect of micelle structure, ionic strength, pH, and temperature. Biophys J. 2002;83(4):2219-30. doi: 10.1016/S0006-3495(02)73982-9, PMID 12324439.

6. Israelachvili JN. Contrasts between Intermolecular, Interparticle, and Intersurface Forces, book chapter. In: Intermol. Surf Forces; 2011. p. 20522 . 
7. Skoglund S, Blomberg E, Wallinder IO, Grillo I, Pedersen JS, Bergström LM. A novel explanation for the enhanced colloidal stability of silver nanoparticles in the presence of an oppositely charged surfactant. Phys Chem Chem Phys. 2017;19(41):28037-43. doi: 10.1039/c7cp04662f, PMID 28994441.

8. Wong FWF, Ariff AB, Stuckey DC. Downstream protein separation by surfactant precipitation: a review. Crit Rev Biotechnol. 2018;38(1):31-46. doi: 10.1080/07388551.2017.1312266, PMID 28427287.

9. Itoo FA, Mir JM, Malik NA, Ali A. Density functional aspects and thermodynamic evaluation of sodium dodecyl sulphate in aqueous tartrazine. J King Saud Univ Sci. 2020;32(4):2505-12. doi: 10.1016/j.jksus.2020.04.009.

10. Mir JM, Itoo FA. Experimental-DFT interface of hydrogen bonding description of 1:10 methanol-water solution. J Mol Liq. 2017;247:1-5. doi: org/10.1016/j.molliq.2017.09.094

11. GM P, Maanvizhi S. Fast track usa regulatory approval for drugs to treat emerging infectious diseases: fast track approval. Asian J Pharm Clin Res. 2021;14:1-4.

12. Mahmood Alabdali AY, Chinnappan S, Abd Razik BM, RM, Khalivulla SI, HR, Samein LH. Impact of covid-19 on multiple body organ failure: a review. Int J Appl Pharm. 2021;13(5):54-9. doi: 10.22159/ijap.2021v13i5.42653.

13. Sundararajan. Insights into corona/coronavirus disease 2019 pandemic-opinion versus evidence. Asian J Pharm Clin Res. 2021;14:13-5.

14. Mir JM, Maurya RC. Nitric oxide as a therapeutic option for COVID-19 treatment: a concise perspective. New J Chem. 2021;45(4):1774-84. doi: 10.1039/D0NJ03823G.

15. https://www.nationalgeographic.com/science/2020/04/factors-allow-viruses-infect-humans-coronavirus. [Last accessed on 10 May 2021]

16. Koonin EV, Senkevich TG, Dolja VV. The ancient virus world and evolution of cells. Biol Direct. 2006;1:29. doi: 10.1186/1745-6150-1-29, PMID 16984643.

17. McIntosh $\mathrm{K}$, Halonen $\mathrm{P}$, Ruuskanen $\mathrm{O}$. Report of a workshop on respiratory viral infections: epidemiology, diagnosis, treatment, and prevention. Clin Infect Dis. 1993;16(1):151-64. doi: 10.1093/clinids/16.1.151, PMID 8383547.

18. Ada GL, Jones PD. The immune response to influenza virus infection. Curr Top Microbiol Immunol 1986;128:1-54.

19. Wiley DC, Skehel JJ. The structure and function of the hemagglutinin membrane glycoprotein of influenza virus. Annu Rev Biochem. 1987;56:365-94. doi: 10.1146/annurev.bi.56.070187.002053, PMID 3304138.

20. Sturman LS, Ricard CS, Holmes KV. Conformational change of the coronavirus peplomer glycoprotein at pH 8.0 and 37 degrees C correlates with virus aggregation and virus-induced cell fusion. J Virol. 1990;64(6):3042-50. doi: 10.1128/JVI.64.6.3042-3050.1990, PMID 2159562.

21. Chepurnov AA, Bakulina LF, Dadaeva AA, Ustinova EN, Chepurnova TS, Baker JR. Inactivation of Ebola virus with a surfactant nanoemulsion. Acta Trop. 2003;87(3):315-20. doi: 10.1016/S0001-706X(03)00120-7, PMID 12875924.

22. Hiemstra PS. Epithelial antimicrobial peptides and proteins: their role in host defence and inflammation. Paediatr Respir Rev. 2001;2(4):30610. doi: 10.1053/prrv.2001.0165, PMID 12052302.

23. Backer JA, Klinkenberg D, Wallinga J. Incubation period of 2019 novel coronavirus (2019-nCoV) infections among travellers from Wuhan, China, 20-28 January 2020. Euro Surveill. 2020;25(5). doi: 10.2807/1560-7917.ES.2020.25.5.2000062, PMID 32046819.

24. Bitko V, Musiyenko A, Barik S. Viral infection of the lungs through the eye. J Virol. 2007;81(2):783-90. doi: 10.1128/JVI.01437-06, PMID 17050596.

25. Rothe C, Schunk M, Sothmann P, Bretzel G, Froeschl G, Wallrauch C, Zimmer T, Thiel V, Janke C, Guggemos W, Seilmaier M, Drosten C, Vollmar P, Zwirglmaier K, Zange S, Wölfel R, Hoelscher M. Transmission of 2019-nCoV infection from an asymptomatic contact in Germany. N Engl J Med. 2020;382(10):970-1. doi: 10.1056/NEJMc2001468.

26. Zou L, Ruan F, Huang M, Liang L, Huang H, Hong Z, Yu J, Kang M, Song Y, Xia J, Guo Q, Song T, He J, Yen HL, Peiris M, Wu J. SARS-CoV-2 viral load in upper respiratory specimens of infected patients. N Engl J Med. 2020;382(12):1177-9. doi: 10.1056/NEJMc2001737, PMID 32074444.

27. Fukushi M, Yamashita M, Miyoshi Akiyama T, Kubo S, Yamamoto K, Kudo K. Laninamiviroctanoate and artificial surfactant combination therapy significantly increases survival of mice infected with lethal influenza H1N1 virus. PLOS One.2012;7(8):e42419. doi: 10.1371/journal.pone.0042419, PMID 22879974.

28. Hsieh IN, De Luna X, White MR, Hartshorn KL. The role and molecular mechanism of action of surfactant protein D in innate host defense against influenza A virus. Front Immunol. 2018;9:1368. doi: 10.3389/fimmu.2018.01368, PMID 29951070.

29. Guttentag S, Foster CD. Update in surfactant therapy. NeoReviews. 2011;12(11):e625-34. doi: 10.1542/neo.12-11-e625.

30. Jeon GW. Surfactant preparations for preterm infants with respiratory distress syndrome: past, present, and future. Korean J Pediatr. 2019;62(5):155-61. doi: 10.3345/kjp.2018.07185, PMID 30744318.

31. Walther FJ, Gordon LM, Waring AJ. Advances in synthetic lung surfactant protein technology. Expert Rev Respir Med. 2019;13(6):499-501. doi: 10.1080/17476348.2019.1589372, PMID 30817233.

32. Bocking T, Johnson L, Singh A, Desai A, Aulakh GK, Singh B. Research article expression of surfactant protein-A and D, and CD9 in lungs of 1 and 30 day old foals. BMC Vet Res. 2021;17(1):236. doi: 10.1186/s12917-021-02943-5, PMID 34225699.

33. Hammad MA, Müller BW. Increasing drug solubility by means of bile salt-phosphatidylcholine-based mixed micelles. Eur J Pharm Biopharm. 1998;46(3):361-67. doi: 10.1016/s0939-6411(98)00037-x, PMID 9885310.

34. Li J, Wang X, Zhang T, Wang C, Huang Z, Luo X, Deng Y. A review on phospholipids and their main applications in drug delivery systems. Asian J Pharm Sci. 2015;10(2):81-98. doi: 10.1016/j.ajps.2014.09.004.

35. van Hoogevest P, Wendel A. The use of natural and synthetic phospholipids as pharmaceutical excipients. Eur J Lipid Sci Technol. 2014;116(9):1088-107. doi: 10.1002/ejlt.201400219, PMID 25400504.

36. Yang C, Wu T, Qi Y, Zhang Z. Recent advances in the application of vitamin E TPGS for drug delivery. Theranostics. 2018;8(2):464-85. doi: $10.7150 /$ thno.22711, PMID 29290821. 